\title{
Effects of respiratory syncytial virus persistence on airway responsiveness and inflammation in guinea-pigs
}

\author{
A.M. Bramley, T.Z. Vitalis, B.R. Wiggs, R.G. Hegele
}

\begin{abstract}
Effects of respiratory syncytial virus persistence on airway responsiveness and inflammation in guinea-pigs. A.M. Bramley, T.Z. Vitalis, B.R. Wiggs, R.G. Hegele. C) ERS Journals Ltd 1999.

ABSTRACT: Recurrent wheezing and asthma often develop after acute respiratory syncytial virus (RSV) bronchiolitis, but the mechanisms of these sequelae are poorly understood. Using a guinea-pig model of human RSV lung infection, the effects of long-term viral persistence on three hallmarks of asthma: nonspecific airway responsiveness, airway inflammation and airway remodelling were examined.

Guinea-pigs were studied 100 days after intranasal instillation of either human RSV or uninfected vehicle, using: 1) acetylcholine challenge to test for airway hyperresponsiveness (AHR); 2) lung histology to quantify the numbers of airway eosinophils and metachromatic cells (mast cells/basophils); 3) airway morphometry of the areas of the airway subepithelial connective tissue, smooth muscle and adventitia, to test for airway remodelling; and 4) immunohistochemistry to identify lung cells containing RSV antigens.

The RSV-inoculated group had significantly elevated AHR and airway eosinophils compared to uninfected control animals $(p<0.05)$. There were no significant differences between the two groups in terms of numbers of airway metachromatic cells, or the areas of subepithelial connective tissue, smooth muscle or adventitia. Viral proteins were identified by immunohistochemistry within several types of lung cells.

In conclusion, long-term persistence of respiratory syncytial virus in the guinea-pig lung is associated with airway hyperresponsiveness and airway eosinophilia, and these changes may be pertinent to the pathogenesis of postbronchiolitis wheezing and asthma in children.
\end{abstract}

Eur Respir J 1999; 14: 1061-1067.

Children hospitalized for acute bronchiolitis from respiratory syncytial virus (RSV) infection frequently go on to develop asthma symptoms [1,2], but the mechanisms of these sequelae are poorly understood. Several animal models have been developed to study mechanisms of virusinduced airway hyperresponsiveness (AHR) [3-6]. For example, juvenile rats experimentally infected with parainfluenza type-1 (Sendai) virus show AHR lasting for at least 90 days, with structural changes to the airway wall that include increased numbers of mast cells [4] and fibrosis [7]. In a guinea-pig model of experimental human RSV infection, RIEDEL et al. [8] have documented the persistence of viral antigens and AHR for at least 6 weeks post-inoculation. The authors of this report have also documented chronic RSV persistence within the guineapig lung, by isolating replicating virus for at least 60 days post-inoculation [9], and showing persistence of the viral genome at 125 days [10]. Furthermore, for at least 60 days post-inoculation, the airways of ' RSV-inoculated animals have significantly increased granulocyte infiltrates [9], while increased numbers of eosinophils are recovered in bronchoalveolar lavage fluids [11].

Asthma is a condition characterized by nonspecific AHR and is histologically associated with chronic airway inflammation that has a prominent component of eosinophils and lymphocytes [12]. Morphometric studies have established that the airways of asthmatic patients show a
University of British Columbia, Pulmonary Research Laboratory St. Paul's Hospital, Vancouver BC, Canada V6Z 1Y6

Correspondence: R.G. Hegele

University of British Columbia

Pulmonary Research Laboratory

St. Paul's Hospital

1081 Burrard Street

Vancouver BC

Canada V6Z 1 Y6

Fax: 6048068351

Keywords: Acute bronchiolitis airway hyperresponsiveness

asthma

guinea-pigs

morphometry

respiratory syncytial virus

Received: April 211999

Accepted after revision July 211999

This work was supported by the Medical Research Council of Canada (MT-13766). R.G. Hegele is the recipient of a Scholarship Award from the Medical Research Council of Canada/British Columbia Lung Association. thickening (remodelling) of the various compartments (subepithelial connective tissue (also called, "lamina propria" or "submucosa"), smooth muscle and adventitia) of the airway wall [13]. It is unknown whether RSV-inoculated guinea-pigs continue to show AHR and airway inflammation beyond 60 days post-inoculation, or whether airway remodelling occurs. Therefore, it was decided to investigate the effects of long-term RSV persistence on possible physiological, inflammatory and morphometric changes in the guinea-pig lung. The specific objectives of this study were to compare RSV-inoculated and uninfected guinea-pigs at 100 days post-inoculation, in terms of: 1) responses to inhalational acetylcholine (ACh) challenge for AHR; 2) numbers of airway eosinophils [12] and metachromatic cells (mast cells/basophils) [4] as indices of airway inflammation; 3 ) airway morphometry of the areas of subepithelial connective tissue, smooth muscle and adventitia as indices of remodelling [13]; and 4) immunohistochemistry for the identification of RSV proteins within specific lung cells.

\section{Methods}

Virus

Human Long strain, type A RSV (American Type Culture Collection (ATCC), Rockville, MD, USA) was propagated in $\mathrm{HEp}-2$ cell monolayers at $37^{\circ} \mathrm{C}$ and $5 \%$ 
$\mathrm{CO}_{2}$, in air. Culture medium consisted of minimal essential medium (MEM) (Gibco BRL, Grand Island, NY, USA) supplemented with $2 \%$ heat-inactivated foetal bovine serum (Hyclone Laboratories Inc., Logan, UT, USA), 0.292 $\mathrm{mg} \cdot \mathrm{mL}^{-1} \mathrm{l}$-glutamine (Gibco BRL) and $50 \mu \mathrm{g} \cdot \mathrm{mL}^{-1}$ gentamicin (Gibco BRL). After 5 days, culture fluids underwent centrifugation $\left(10,000 \times \mathrm{g}\right.$, for $10 \mathrm{~min}$ at $\left.4^{\circ} \mathrm{C}\right)$ to remove cell debris. The clear, virus-containing supernatant was concentrated by ultrafiltration through Centriprep- 100 concentrator devices (Amicon, Oakville, ON, Canada). Viral stocks were kept at $-70^{\circ} \mathrm{C}$ and used for inoculation of animals within 1 week of storage. Supernatants of uninfected, HEp-2 cell cultures were similarly prepared for inoculation of control animals.

\section{Inoculation protocol}

One month-old, female Cam-Hartley guinea-pigs (Charles River Laboratories, Montreal, QC, Canada) weighing 250-300 g were housed in filter-isolated, polycarbonate cages and were acclimatized for 1 week before experimentation. Animals were exposed to alternating 12-h lightdark cycles, and had free access to food and water, in accordance with the standards of the Canadian Council on Animal Care [14]. Under light anaesthesia (3-5\% halothane), guinea-pigs were inoculated intranasally with 200 $\mu \mathrm{L}$ of either RSV suspension $\left(4.5 \times 10^{4}\right.$ plaque forming units (pfu.animal ${ }^{-1}$ ) or sham, uninfected medium, prewarmed at $37^{\circ} \mathrm{C}$. Infected animals were housed in a different room from the uninfected animals.

\section{Experimental design}

Forty guinea-pigs were randomized into four equal groups, with 20 animals (10 RSV-inoculated, 10 control animals) used for measurement of AHR and 20 animals (10 RSV-inoculated, 10 control animals) used for lung histological, morphometric and immunohistochemical analyses. Guinea-pigs were randomized in this manner because it has recently been shown that the measurement of AHR by ACh challenge can produce artifactual increases in the adventitial area of guinea-pig airways [15].

\section{Airway hyperresponsiveness measurement}

The protocol for ACh challenge was identical to the method described by DAKHAMA et al. [16] in allergically sensitized and RSV-infected guinea-pigs. Briefly, animals were anaesthetized with intraperitoneal ketamine (50 $\left.\mathrm{mg} \cdot \mathrm{mL}^{-1}\right)$ and xylazine $\left(10 \mathrm{mg} \cdot \mathrm{mL}^{-1}\right)$, and anaesthesia was maintained with $1-2 \%$ halothane. A tracheotomy was perormed, a saline-filled oesophageal catheter was inserted through the mouth, and the animal was placed in a body plethysmograph. Guinea-pigs were paralysed with succinylcholine $\left(0.5 \mathrm{mg} \cdot \mathrm{kg}\right.$ body weight $\left.{ }^{-1}\right)$, and were ventilated with a small animal ventilator (Harvard Instruments Corporation, South Natick, MA, USA) at a rate of 60 breaths $\cdot \mathrm{min}^{-1}$ and a tidal volume of $3 \mathrm{~mL}$. Pulmonary resistance $(R \mathrm{~L})$ was calculated at baseline, following nebulized saline and after each dose of ACh at 0.5, 1.5, 5, 15 and $50 \mathrm{mg} \cdot \mathrm{mL}^{-1}$. ACh was administered as six tidal breaths with a flow rate of $8 \mathrm{~L} \cdot \mathrm{min}^{-1}$. It was ensured that the transpulmonary pressure had returned to baseline prior to the administration of the next dose of ACh. $R \mathrm{~L}$ was calculated from the electronically differentiated volume signal, deriving flow and the transpulmonary pressure according to the method of NEERGAARD and WIRZ [17], using a software package incorporating ANADAT (Raytech Instruments, Vancouver, BC, Canada) and expressed as absolute change $\mathrm{cmH}_{2} \mathrm{O} \cdot \mathrm{mL}^{-1} \cdot \mathrm{s}$.

\section{Airway inflammation}

Histological evaluation of airway inflammation consisted of counting the numbers of eosinophils and metachromatic cells (mast cells/basophils) in the airway wall. Briefly, the left lung was inflated with a mixture of optimum cutting temperature (OCT) compound (Miles Scientific, Elkhart, IL, USA) and 4\% paraformaldehyde in phosphate-buffered saline (PBS), and longitudinal slices were fixed for $24 \mathrm{~h}$ before processing in paraffin. Consecutive, $5-\mu \mathrm{m}$ paraffin sections were stained with: 1) haematoxylin and eosin for routine histological examination; 2) Masson's trichrome stain for morphometric measurement of the airway's subepithelial basement membrane perimeter $(\mathrm{Pbm})$; 3) Hansel's stain for identification of eosinophils; and 4) toluidine blue for the identification of metachromatic cells [18]. Slides were coded such that that observer did not know whether a given slide originated from an RSV- or sham-inoculated animal. The numbers of eosinophils and mast cells were expressed per unit area of airway wall, normalized to airway size ( $\mathrm{Pbm})$ [ 19].

\section{Airway morphometry}

Using a laser mouse on a digitizing pad and the Bioquant IV software image analysis system (R\&M Systems, Nashville, TN, USA), the following airway perimeters were traced: 1) subepithelial basement membrane (Pbm); 2) inner border of airway smooth muscle; 3 ) outer border of airway smooth muscle; and 4) serosal border. The Bioquant software automatically calculated the areas associated with these perimeters, such that the areas of three compartments of the airway wall were obtained: subepithelial connective tissue (Wse), area of airway smooth muscle $\left(\mathrm{W}_{\mathrm{sm}}\right)$, and adventitial area ( $\left.\mathrm{W}_{\mathrm{o}}\right)$. Up to 10 small

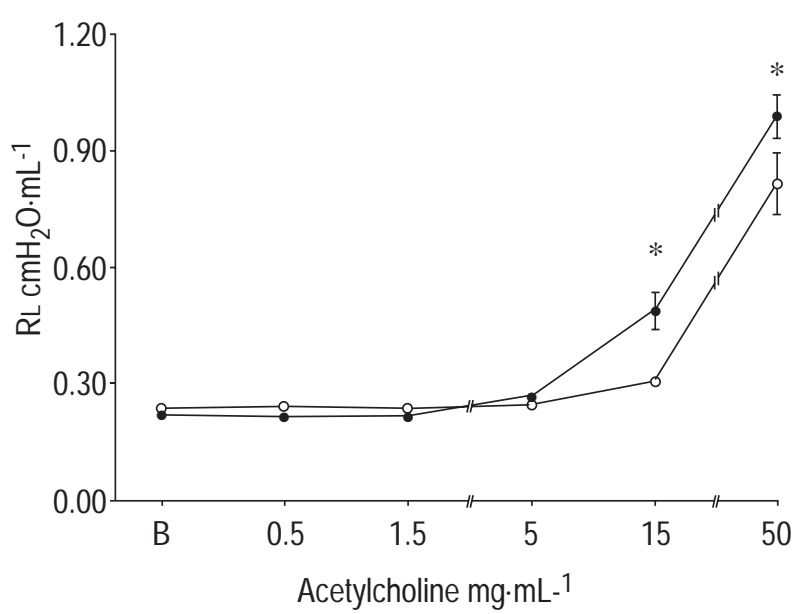

Fig. 1. - Results of acetylcholine (ACh) challenge (mean \pm SEM) for airway hyperresponsiveness (AHR) for respiratory syncytial virus (RSV)inoculated (O) versus control $(\bigcirc)$ groups of guinea-pigs. Note that the RSV-inoculated group has significantly higher pulmonary resistance $R \mathrm{~L}$ $(*: \mathrm{p}<0.05)$ at $\mathrm{ACh}$ doses of 15 and $50 \mathrm{mg} \cdot \mathrm{mL}^{-1}$. B: baseline (i.e. ACh dose was zero). 
and mid-sized noncartilaginous airways were studied per lung section from all 20 slides in designated RSV-inoculated and control animals. Results were expressed as the areas of airway wall compartment associated with each $\mathrm{Pbm}$. Previous experiments in RSV-infected guinea-pigs established that the inter- and intra-observer variation using the Bioquant system was less than that of the distribution of compartmental areas for a given $\mathrm{Pbm}$ [5].

\section{Respiratory syncytial virus immunohistochemical}

The protocol for immunohistochemical identification of RSV proteins in lung sections was similar to a previously
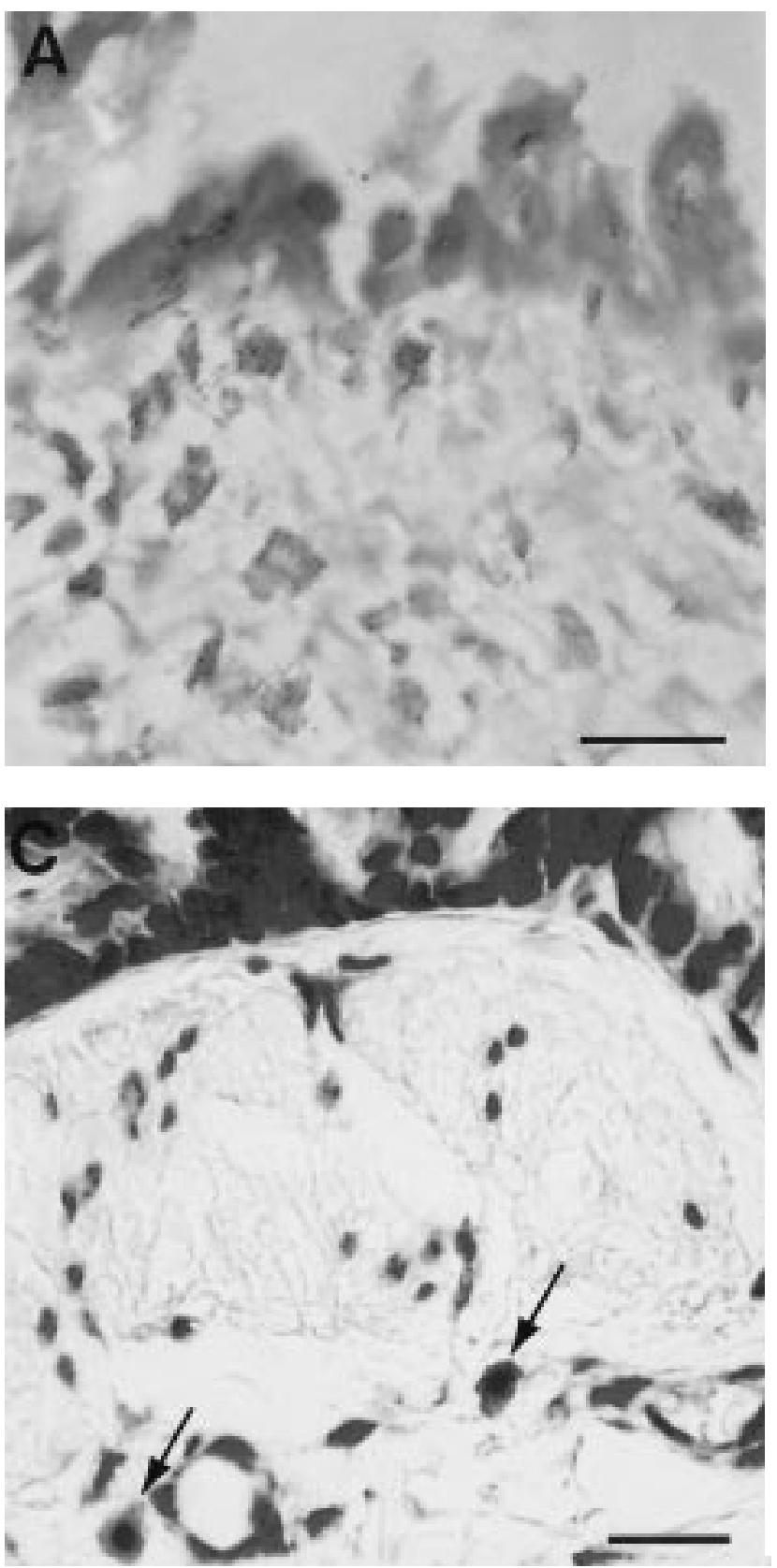

Fig. 2. - Photomicrographs of guinea-pig airways stained with Hansel stain for eosinophils (A and B) and toluidine blue stain for metachromatic cells $(\mathrm{C}$ and $\mathrm{D})$ in respiratory syncytial virus-infected (A and C) and control animals (B and D). Note the prominent eosinophil infiltrate (staining cells) in the airway of the RSV-inoculated animal in comparison to the control animal (A versus B), while only occasional metachromatic cells (arrows) are identified in the airways of the two groups of animals (C versus $\mathrm{D})$. (Internal scale bars $=30 \mu \mathrm{m}$.)
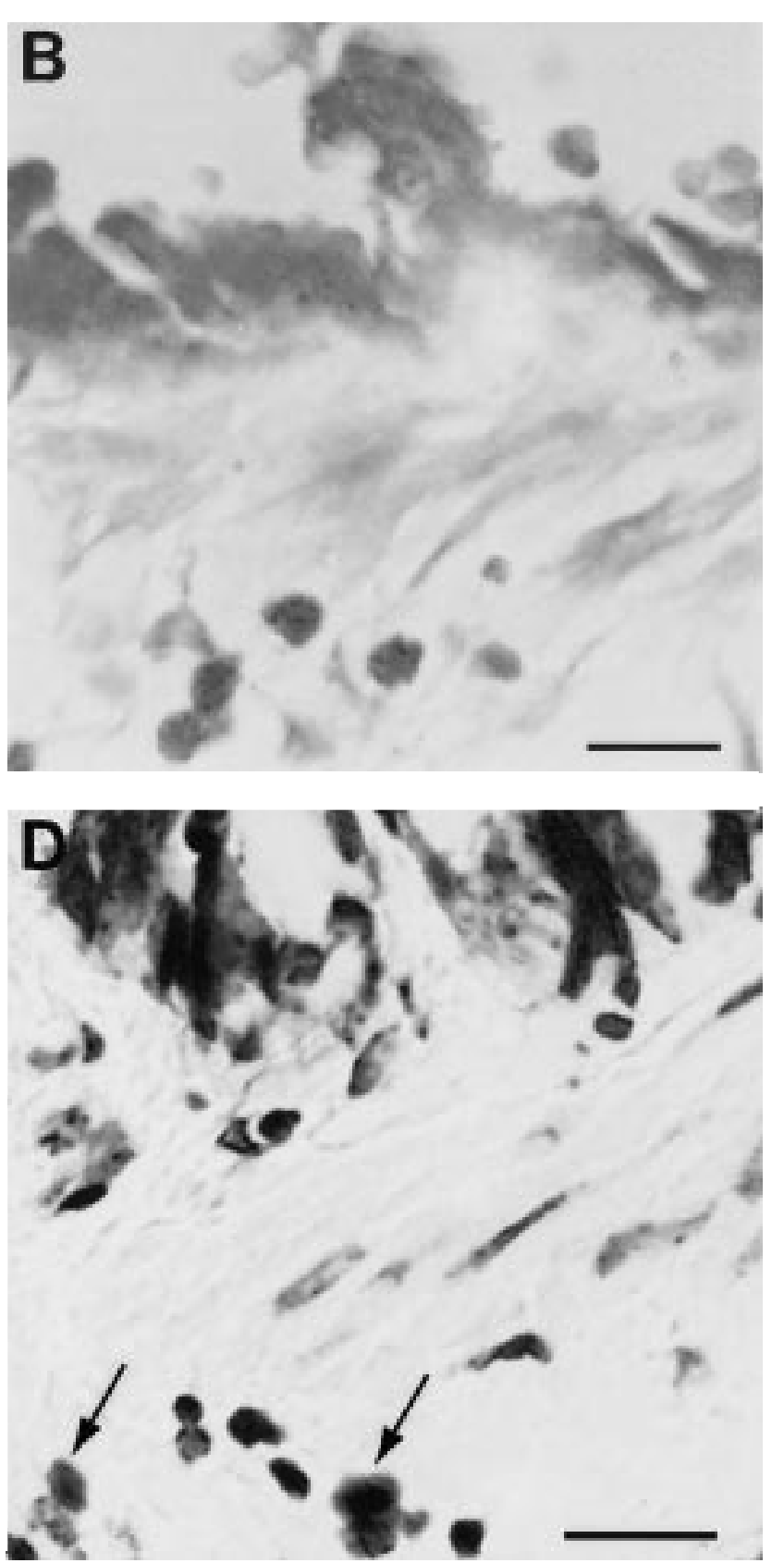

described method [20]. Paraformaldehyde-fixed, paraffinembedded lung sections were pretreated with $0.1 \%$ protease, type XIV, (Sigma Chemical, St. Louis, MO, USA) in $0.5 \mathrm{M}$ Tris-buffered saline (TBS), $\mathrm{pH} 7.6\left(37^{\circ} \mathrm{C}, 10 \mathrm{~min}\right)$; washed at room temperature in tap water and $95 \%$ ethanol, incubated with $0.9 \% \mathrm{H}_{2} \mathrm{O}_{2}$ in methanol for $25 \mathrm{~min}$, and further washed in tap water and TBS. After blocking in normal swine serum (DAKO, Carpenteria, CA, USA), diluted 1:20 in primary antibody diluting buffer (Biomedia, Foster City, CA, USA) (30-min at room temperature), sections were incubated $(90 \mathrm{~min}$. at room temperature) with primary rabbit anti-RSV antibody (B344; DAKO), diluted $1: 300$ in $\mathrm{TBS} / 2 \%$ bovine serum albumin (BSA) 
fraction $\mathrm{V} / 1 \%$ human $\mathrm{AB}$ serum. A 5 min wash in TBS was followed by incubation (45 min at room temperature) with biotinylated swine anti-rabbit secondary antibody (DAKO), diluted 1:300 in TBS/2\% BSA $/ 1 \%$ human $\mathrm{AB}$ serum. After washing in TBS, sections were incubated (45 $\mathrm{min}$ at room temperature) in peroxidase-conjugated streptavidin (DAKO), diluted 1:600 In TBS 12\% BSA/ $1 \%$ human AB serum, and washed again in TBS. Sections were developed at room temperature in $20 \mu \mathrm{L}$ working 3-amino-9-ethylcarbazole (AEC) solution (1 drop of 3amino-9-ethylcarbazole) (Sigma), 1 drop $3 \% \mathrm{H}_{2} \mathrm{O}_{2}$ in $3 \mathrm{~mL}$ $0.1 \mathrm{M}$ sodium acetate, $\mathrm{pH}$ 5.2) for $15 \mathrm{~min}$, rinsed in distilled water, and counterstained with Meyer's haematoxylin. Coverslips were mounted using aqueous mounting medium. Positive controls included lung sections from culture-proven, RSV-infected guinea-pig and human lungs, while negative controls consisted of lung sections from uninfected, control guinea-pigs. Results were interpreted as "positive" (brown colour observed) or "negative" (no immunostaining observed).

\section{Statistical analysis}

Values are presented as mean \pm SEM. Measurements of lung mechanics were analysed by one way repeated measures analysis of variance (ANOVA), with a Bonferroni correction to account for multiple comparisons [21]. The number of airway eosinophils and metachromatic cells in the RSV-inoculated and control groups were compared by use of a t-test for equality of means, with a p-value $<0.05$ considered to be significant. The airway compartmental areas of RSV-inoculated and control guinea-pigs were compared by use of the random effects linear regression analysis of FeLdman [22], in which $\mathrm{W}_{\text {se }} \mathrm{W}_{\text {sm }}$ and $\mathrm{Wo}_{\mathrm{o}}$ underwent a square root transformation, and each of these determinants was plotted against $\mathrm{Pbm}$, to obtain a linear relationship. To obtain a sensitive index of any differences in compartmental areas between the two groups of guinea-pigs, the square root of each determinant (at each $\mathrm{Pbm}$ ) was subtracted between the RSV-infected and control animals. These differences (with 95\% confidence limits) were plotted, such that statistical significance was present if the $95 \%$ confidence limits did not include zero (i.e., a value of zero in this analysis indicates no significant difference between the two groups).

\section{Results}

\section{Airway hyperresponsiveness measurement}

Figure 1 shows the results of AHR for RSV-inoculated and control guinea-pigs. The two groups showed similar

Table 1. - Airway eosinophils and metachromatic cells

\begin{tabular}{lccc}
\hline Cell type & Group & $\mathrm{n}$ & $\begin{array}{c}\text { Number of } \\
\text { cells } \cdot \mathrm{mm}^{-2} \cdot \mathrm{Pbm}^{-1} \cdot \text { animal }^{-1}\end{array}$ \\
\hline Eosinophils & RSV & 10 & $1106 \pm 245^{*}$ \\
& Control & 10 & $558 \pm 58$ \\
Metachromatic cells & RSV & 10 & $18 \pm 6$ \\
& Control & 10 & $6 \pm 3$ \\
\hline
\end{tabular}

Data are number or mean \pm SEM. Pbm: basement membrane perimeter; RSV: respiratory syncytial virus. ${ }^{*}: \mathrm{p}<0.05$.

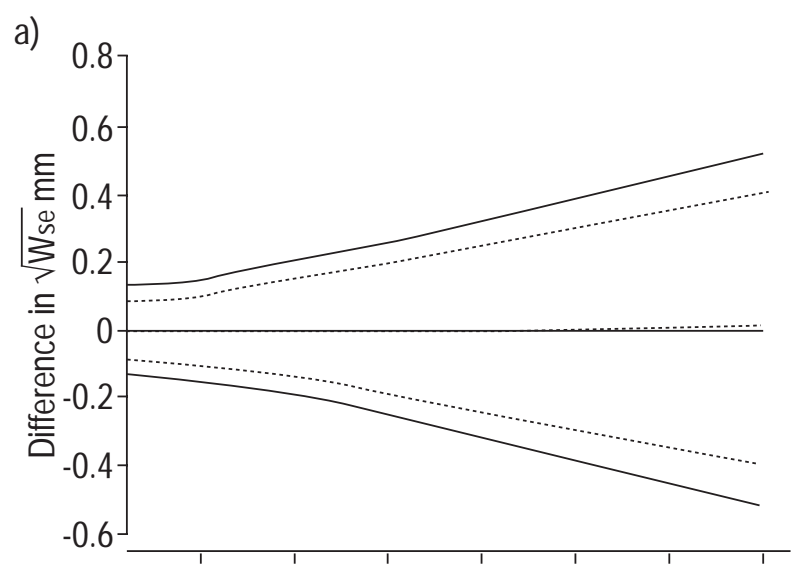

b)

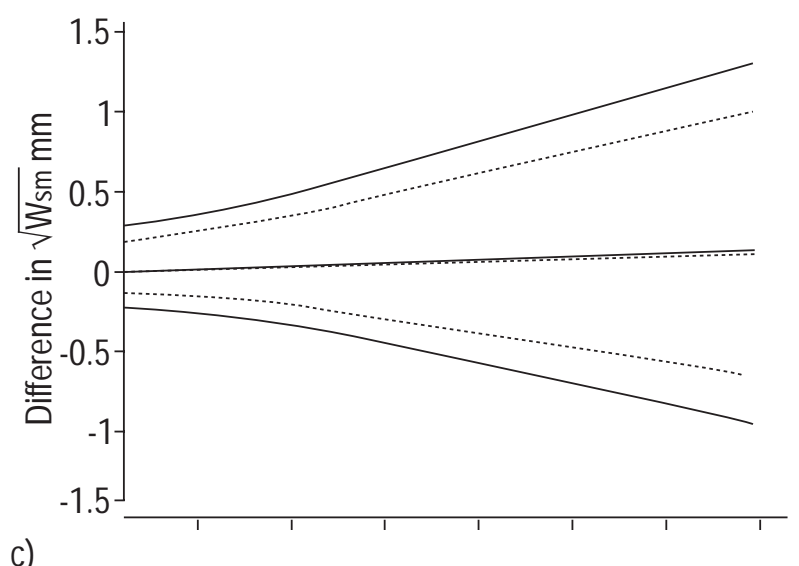

c)

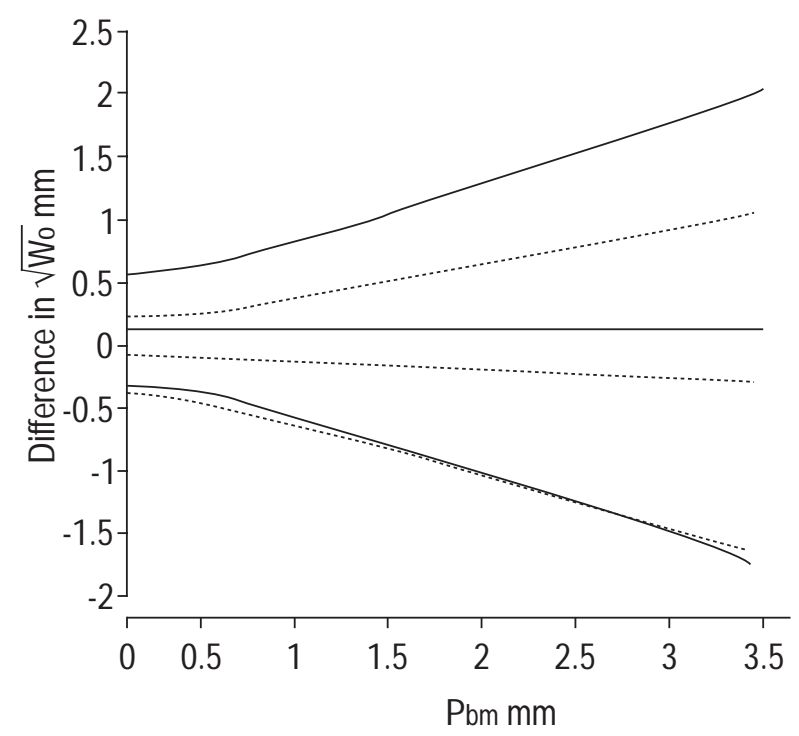

Fig. 3. - Results of airway morphometry for areas of subepithelial connective tissue (a), airway smooth muscle (b) and airway adventitia (c) between respiratory syncytial virus (RSV)-inoculated $(-)$ and control (- - - ) guinea-pigs. These plots show the estimated relationship difference, based on random effects linear regression, between RSVinoculated and control guinea-pigs. The regression relationship shows the average expected difference and the outer lines indicate the $95 \%$ confidence interval (CI) for this difference. Since all 95\% CIs include zero, there are no statistically significant differences between the two groups of animals. Pbm: basement membrane perimeter; We: adventitial area; Wsm: airway smooth muscle area; Wse: subepithelial connective tissue area. 

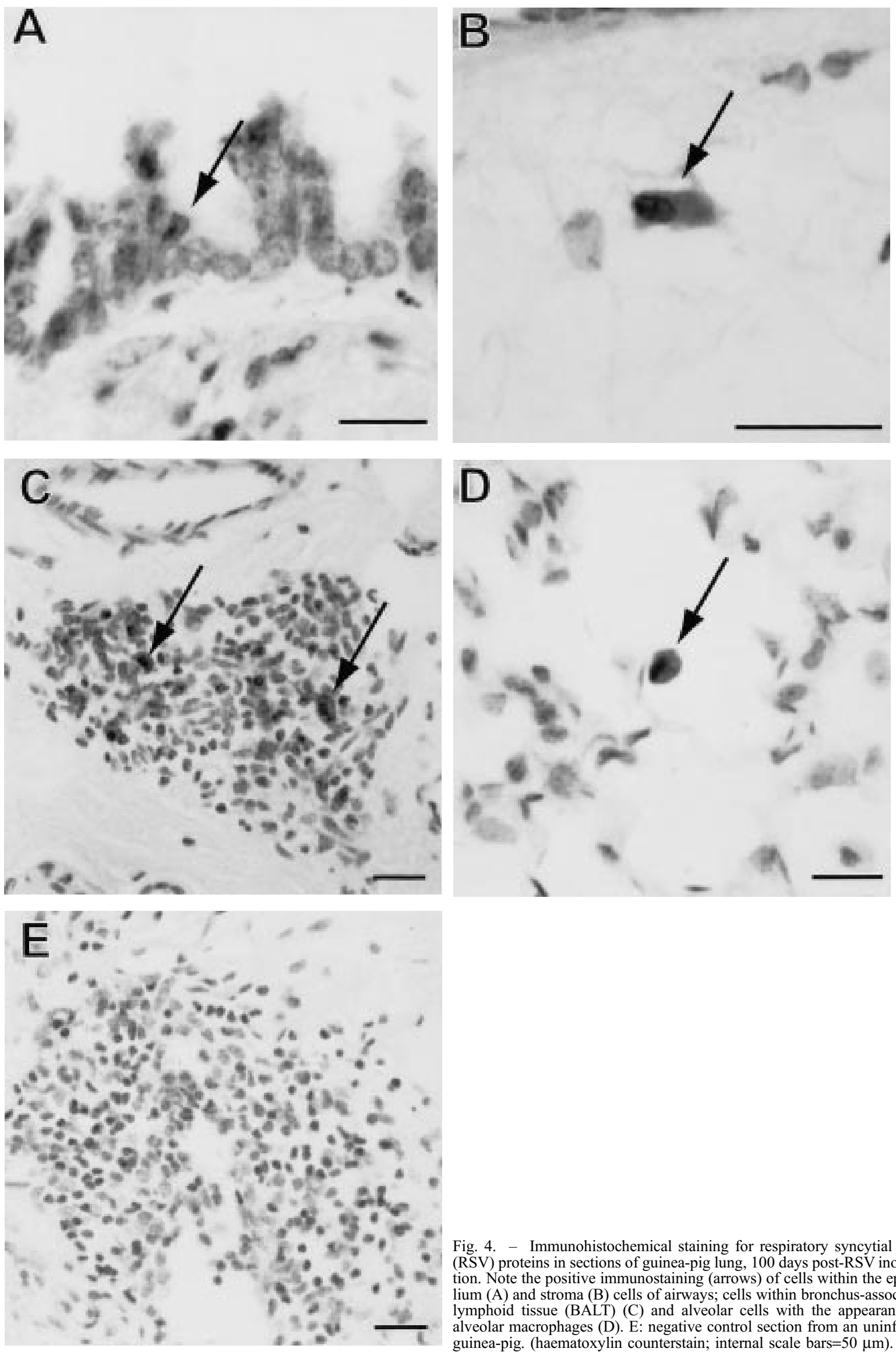

Fig. 4. - Immunohistochemical staining for respiratory syncytial virus (RSV) proteins in sections of guinea-pig lung, 100 days post-RSV inoculation. Note the positive immunostaining (arrows) of cells within the epithelium (A) and stroma (B) cells of airways; cells within bronchus-associated lymphoid tissue (BALT) (C) and alveolar cells with the appearance of alveolar macrophages (D). E: negative control section from an uninfected guinea-pig. (haematoxylin counterstain; internal scale bars $=50 \mu \mathrm{m}$ ). 
values for $R \mathrm{~L}$ at baseline and at the lower doses of $\mathrm{ACh}$ challenge (up to $5 \mathrm{mg} \cdot \mathrm{mL}^{-1}$ ). At ACh challenge doses of $15-50 \mathrm{mg} \cdot \mathrm{mL}^{-1}$, the $R \mathrm{~L}$ of the RSV-inoculated group was significantly higher than that of the control group $(p<0.05)$, indicative of a significant increase in AHR in the group of virus-inoculated animals.

\section{Airway inflammation}

Figure 2 shows photomicrographs of Hansel-stained and toluidine-blue stained sections of airways from RSVinoculated and control guinea-pigs that were studied 100 days post-inoculation. The results of eosinophil and metachromatic cell counts in the airways of the two groups of animals are summarized in table 1 . There were significantly more airway eosinophils per unit area in the RSVinoculated guinea-pigs in comparison to controls $(\mathrm{p}<0.05)$. In contrast, there were no significant differences in airway metachromatic cells between the two groups of animals.

\section{Airway morphometry}

Figure 3 shows the results of the morphometric analysis of wall areas of subepithelial connective tissue, airway smooth muscle and adventitial layers. A total of 168 airways were studied for $10 \mathrm{RSV}$-inoculated and 10 control animals, and there were no significant differences in the various wall areas measured between the two groups of animals.

\section{Respiratory syncytial virus immunostaining}

Figure 4 shows results of immunohistochemical staining for RSV proteins in sections of guinea-pig lungs. Viral proteins were identified in occasional cells in the lungs of all RSV-inoculated animals examined. Intracytoplasmic RSV proteins were detected in cells within the airway epithelium and stroma, bronchus-associated lymphoid tissue (BALT) and within the alveolar space (consistent with alveolar macrophages). No false positive immunostaining was observed in lung sections from uninfected control animals.

\section{Discussion}

The purpose of this study was to examine whether longterm persistence of RSV in the guinea-pig lung could result in physiological, histopathological and morphometric changes observed in the airways of asthmatic patients. The results indicate that, after 100 days of inoculating guineapigs with RSV, there is significantly higher $\mathrm{Rl}$ at the higher challenge doses of $\mathrm{ACh}$, indicative of a persistent effect on AHR. Therefore, these findings extend previous work in this animal model of persistent RSV lung infection $[9,10]$, by showing an association between viral persistence and AHR at 100 days. These findings also extend the previous observations of RIEDEL et al. [8], who demonstrated persistent RSV protein and AHR in the guinea-pig lung at 6 weeks post-inoculation.

The results of lung histology indicate that RSV-inoculated guinea-pigs have significantly higher numbers of eosinophils per unit area of airway, but not metachromatic cells, at 100 days post-inoculation, in comparison to uninfected control animals. Increased numbers of eosinophils are observed in asthmatic patients [ 12]. The results are consistent with increase numbers of airway eosinophils being involved to the pathogenesis of AHR in the RSV group, similar to previous observations of airway eosinophilia in ovalbumin-sensitized guinea-pigs with AHR [16]. However, caution is required to link virus-induced airway eosinophilia to AHR, as other investigators have reported that treatment of parainfluenza type 3 virus-infected guinea-pigs with an antibody to interleukin (IL)-5 (an important cytokine for eosinophil maturation) ameliorates AHR without affecting the numbers of eosinophils within the airways [23]. Recently, SchwARZE et al. [24] showed that AHR that develops during acute RSV infection of mice requires eosinophils and IL-5. Further studies are required to determine whether increased levels of IL-5 are present during persistent RSV infection of the guinea-pig lung.

In this study, there were no significant increases in the numbers of metachromatic cells (mast cells/basophils) in the airways of RSV-inoculated guinea-pigs, when compared to control animals. These findings are in apparent contrast with previous observations reported in Sendai virus infected rats [4]. However, it must be noted that the baseline number of mast cells in the current control guinea-pigs were considerably higher than those seen in Sendai virus-infected rats. Therefore, as there are more mast cells at the basal level in guinea-pigs, it may be more difficult to observe significant increases in airway metachromatic cells from RSV infection in the present model.

The lack of apparent virus-associated airway remodelling in this study may be related to 100 days being an insufficient period for remodelling to develop. Alternatively, these findings may indicate that airway remodelling does not occur after acute RSV bronchiolitis. If airway remodelling is not a sequela of acute bronchiolitis in humans, then this may provide a clue to understanding the mechanisms by which some children "outgrow" asthma. To definitively test this hypothesis will require comparisons of airway morphometry between groups of asthmatic and nonasthmatic children.

Only a few lung cells in each RSV-inoculated animal showed positive immunostaining for viral proteins. This staining pattern is typical of so-called "smouldering infections" that are characterized by low levels of viral replication in only a few cells at any given time, with minimal cytolysis [25]. Smouldering infection may therefore be a mechanism of RSV persistence within the lung after the resolution of acute bronchiolitis. Interestingly, the presence of viral proteins within BALT cells suggests that the virus might be stimulating a host immune response. The possibility that local, virus-specific immunity may be related to the pathogenesis of increased airway eosinophils in RSV-inoculated guinea-pigs at 100 days post-inoculation is an intriguing hypothesis that needs further investigation.

In summary, using a guinea-pig model, we have shown persistence of respiratory syncytial virus proteins in the lung at 100 days post-inoculation, and that viral persistence is associated with airway hyperresponsiveness to acetylcholine challenge and increased eosinophilic infiltration of the airways. These findings may be relevant to the pathogenesis of post-bronchiolitis wheezing and asthma in humans, and studies are now warranted to determine if respiratory syncytial virus can similarly persist in affected children. 


\section{References}

1. Sly PD, Hibbert ME. Childhood asthma following hospitalization with acute viral bronchiolitis in infancy. Pediatr Pulmonol 1989; 7: 153-158.

2. Sigurs N, Bjarnason R, Sigurbergsson F, Kjellman B, Bjorksten B. Asthma and immunoglobulin E antibodies after respiratory syncytial virus bronchiolitis: a prospective cohort study with matched controls. Pediatrics 1995; 95: 500-505.

3. Folkerts G, Verheyen A, Nijkamp FP. Viral infection in guinea pigs induces a sustained non-specific airway hyperresponsiveness and morphological changes of the respiratory tract. Eur J Pharmacol 1992; 228: 121-130.

4. Castleman WL, Sorkness RL, Lemanske RF Jr., McAllister PK. Viral bronchiolitis during early life induces increased numbers of bronchiolar mast cells and airway hyperresponsiveness. Am J Pathol 1990; 137: 821-831.

5. Robinson PJ, Hegele RG, Schellenberg RR. Increased airway reactivity in human RSV bronchiolitis in the guinea pig is not due to increased wall thickness. Pediatr Pulmonol 1996; 22: 248-254.

6. Schwarze J, Hamelmann E, Bradley KL, Takeda K, Gelfand EW. Respiratory syncytial virus infection results in airway hyperresponsiveness and enhanced airway sensitization to allergen. J Clin Invest 1997; 100: 226233.

7. Uhl EW, Castleman WL, Sorkness RL, Busse WW, Lemanske RF Jr., McAllister PK. Parainfluenza virusinduced persistence of airway inflammation, fibrosis, and dysfunction associated with TGF- $\beta$ expression in Brown Norway rats. Am J Respir Crit Care Med 1996; 154: 1834-1842.

8. Riedel F, Obersieck B, Streckert H-J, Philippou S, Krusat T, Marek W. Persistence of airway hyperresponsiveness and viral antigen following respiratory syncytial virus bronchiolitis in young guinea-pigs. Eur Respir J 1997; 10: 639-645.

9. Dakhama A, Vitalis TZ, Hegele RG. Persistence of respiratory syncytial virus (RSV) and development of RSV-specific IgG 1 antibodies in a guinea pig model of acute bronebiolitis. Eur Respir J 1997; 10: 20-26.

10. Hegele RG. The role of viruses in chronic respiratory disease. Clin Pulmonol Med 1996; 3: 185-190.

11. Dakhama A, Chan NG, Ahmad HY, Bramley AM, Vitalis TZ, Hegele RG. Usefulness of bronchoalveolar lavage for diagnosis of acute and persistent respiratory syncytial virus lung infections in guinea pigs. Pediatr Pulmonol 1998; 26: 396-404.
12. Hamid Q, Song Y, Kotsimbos TC, et al. Inflammation of small airways in asthma. J Allergy Clin Immunol 1997; 100: 44-51.

13. Kuwano K, Bosken CH, Pare PD, Bal TR, Wiggs BR, Hogg JC. Small airways dimensions in asthma and in chronic obstructive pulmonary disease. Am J Respir Crit Care Med 1993; 148: 1220-1225.

14. Canadian Council on Animal Care. Guide to the care and use of experimental animals. Ottawa, Ontario: CCAC, 1980.

15. Chan NG, Bramley AM, Hegele RG. Comment on the Inspiraplex workshop on airway remodelling in asthma: implications for asthma therapy. Cdn Respir J 1998; 5: 226-231.

16. Dakhama A, Bramley AM, Chan NG, McKay KO, Schellenberg RR, Hegele RG. Effect of respiratory syncytial virus on subsequent sensitisation to ovalbumin in guinea-pigs. Eur Respir J 1999; 13: 976-982.

17. Neergaard K, Wirz K. Die Messung der Stromungswiderstand in den Atemwegen des Menschen, inbesondere bei Asthma und Emphyse. Z Klin Med 1927; 105: 51-82.

18. Drury RAB, Wallington EA. Carleton's Histological Technique. London, UK: Oxford University Press, 1967: 48-137.

19. Bai A, Eidelman DH, Hogg JC, et al. Proposed nomenclature for quantifying subdivisions of the bronchial wall. J Appl Physiol 1994; 77: 1011-1014.

20. Hegele RG, Robinson PJ, Gonzalez S, Hogg JC. Production of acute bronchiolitis in guinea pigs by human respiratory syncytial virus. Eur Respir $J$ 1993; 6: 1324 1331.

21. Godfrey K. Comparing means of several groups. In: Bailar JC III, Mosteller F, eds. Medical Uses of Statistics. Waltham, MA: NEJM Books, 1986: 205-234.

22. Feldman H. Families of lines: random effects in linear regression analysis. J Appl Physiol 1988; 64: 1721-1732.

23. van Oosterhout AJ, van Ark I, Folkerts G, et al. Antibody to interleukin-5 inhibits virus-induced airway hyperresponsiveness to histamine in guinea pigs. Am J Respir Crit Care Med 1995; 151: 177-183.

24. Schwarze J, Cieslewicz G, Hamelmann E, et al. Interleukin-5 and eosinophils are essential for the development of airway hyperresponsiveness following acute respiratory syncytial virus infection. J Immunol 1999; 162: 2991-3004.

25. Ahmed R, Morrison LA, Knipe DM. Viral persistence. In: Nathanson N, Ahmed R, Holmes KV, eds. Viral Pathogenesis. Philadelphia: Lippincott-Raven Publishers, 1997: 181-205. 